\title{
THE EFFICACY OF RADIOIODINE THERAPY IN PATIENTS WITH GRAVES' DISEASE
}

\author{
Anna M.Dabrowska ${ }^{1}$,Jolanta Kijek ${ }^{2}$, Jerzy S.Tarach ${ }^{1}$, Anna Toruń-Jurkowska ${ }^{3}$, \\ Beata Chrapko², Maria Kurowska ${ }^{1}$ \\ 1 Chair and Department of Endocrinology, Medical University of Lublin, Poland \\ 2 Chair and Department of Nuclear Medicine, Medical University of Lublin, Poland \\ 3 Department of Mathematics and Medical Biostatistics, Medical University of Lublin, Poland
}

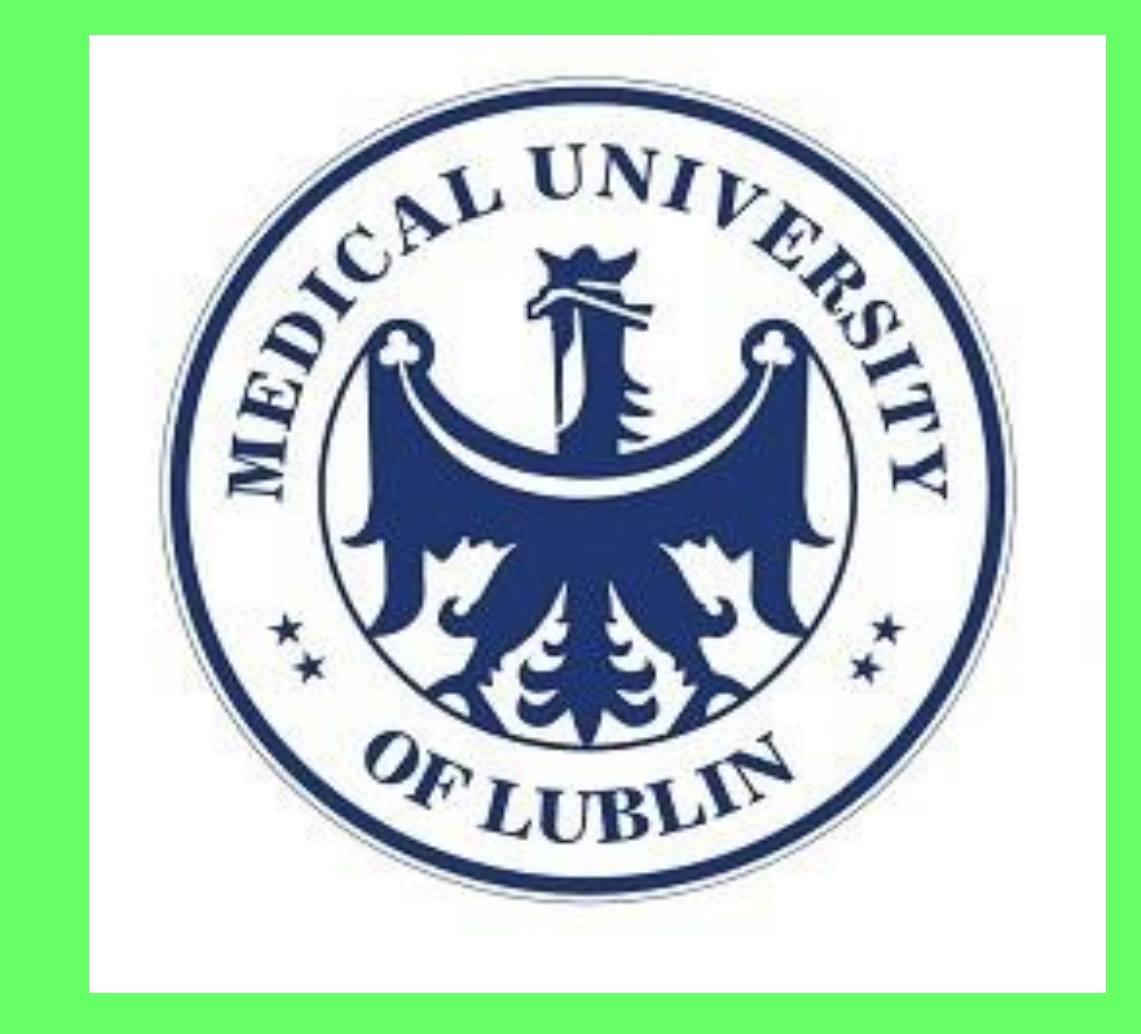

INTRODUCTION: Radioiodine (RAI) has been used for the treatment of Graves' hyperthyroidism since 1940s. It is relatively safe and considered as one of the definitive therapies. Achievement of euthyroidism or hypothyroidism is defined as a successful therapy.

METHODS: The study was conducted in 366 patients ( $80.60 \%$ of women) with Graves' disease (GD), aged $46.76 \pm 13.52$ years. We analyzed retrospectively hormonal and imaging findings (scintigraphy, ultrasonography), including isotopic results in subjects treated at Department of Nuclear Medicine and at Endocrinology Department during the eight-year period. The efficacy of RAI therapy has been assessed based on free thyroid hormones levels, measured 12 months after radioiodine administration.

\section{RESULTS}

- Mean concentrations of thyroid hormones before therapy were: FT4 - 38.40 $\pm 22.17(12.0-22.0 p m o l / I)$ and FT3 - $21.9 \pm 17.11$ (3.0-7.0pmol/I)

- The thyroid mass was estimated to be $69.67 \pm 38.87 \mathrm{~g}$.

- Mean RAI 24-h uptake was $63.93 \pm 16.15 \%$ and therapeutic activity of RAI, calculated using Marinelli's formula, was $544.28 \pm 176.35$ MBq.

- The used thyroid-absorbed doses of RAI (Gy) were: $\leq 120,>120$ and $\leq 150,>150$ ( $49.18 \%$ vs $46.99 \%$ vs $3.83 \%$ of subjects with GD, respectively).

\section{FIG.1 The results of RAI therapy}

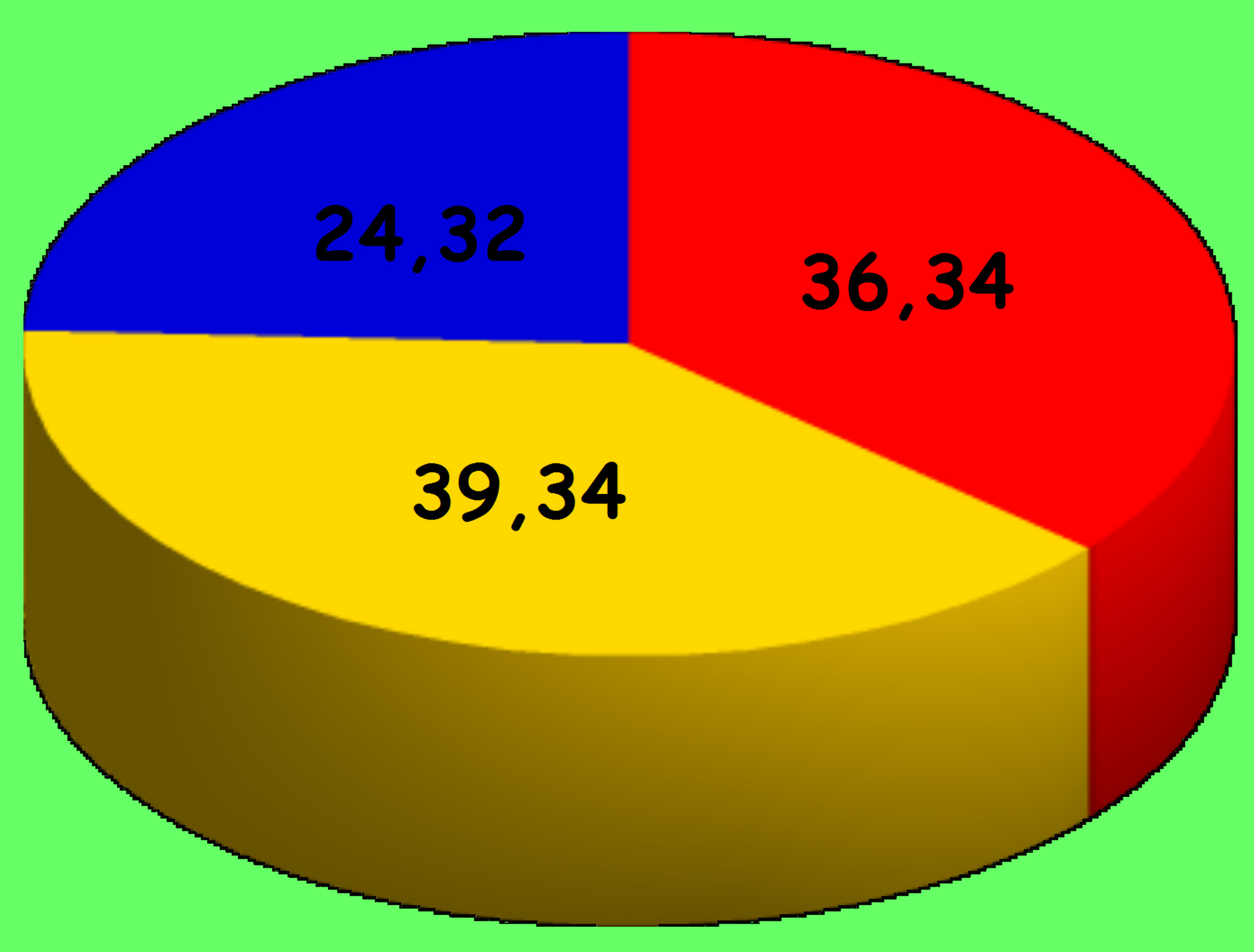

-EUTHYREOSIS - $24.32 \%$ (25.42\% of F, $19.72 \%$ of $M$ with GD)

HYPOTHYROIDISM - $39.34 \%$ (39.34\% of $F, 39.44 \%$ of $M$ with GD)

HYPERTHYROIDISM - $36.34 \%$ (35.26\% of $F, 40.84 \%$ of $M$ with GD)

AN EFFECTIVE CURE OF HYPERTHYROIDISM WAS SIGNIFICANTLY CORRELATED WITH LOWER: thyroid mass / RAI 24-h uptake / administered dose
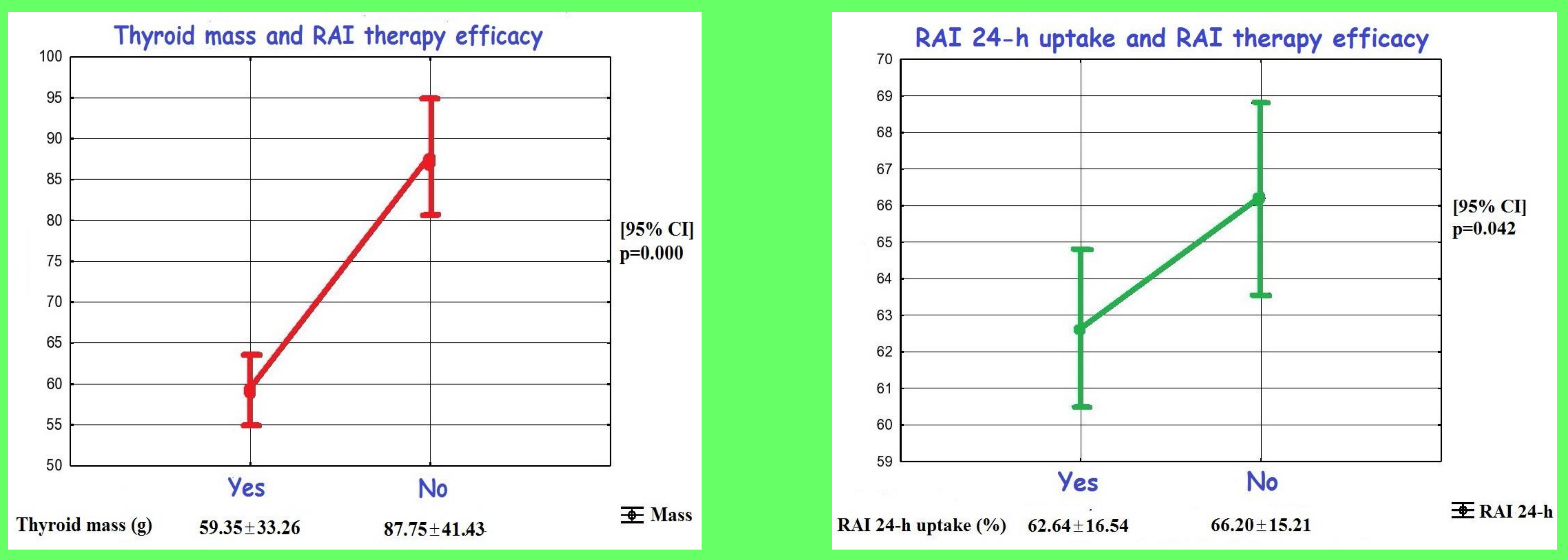

\section{FIG. 2 The efficacy of RAI therapy}

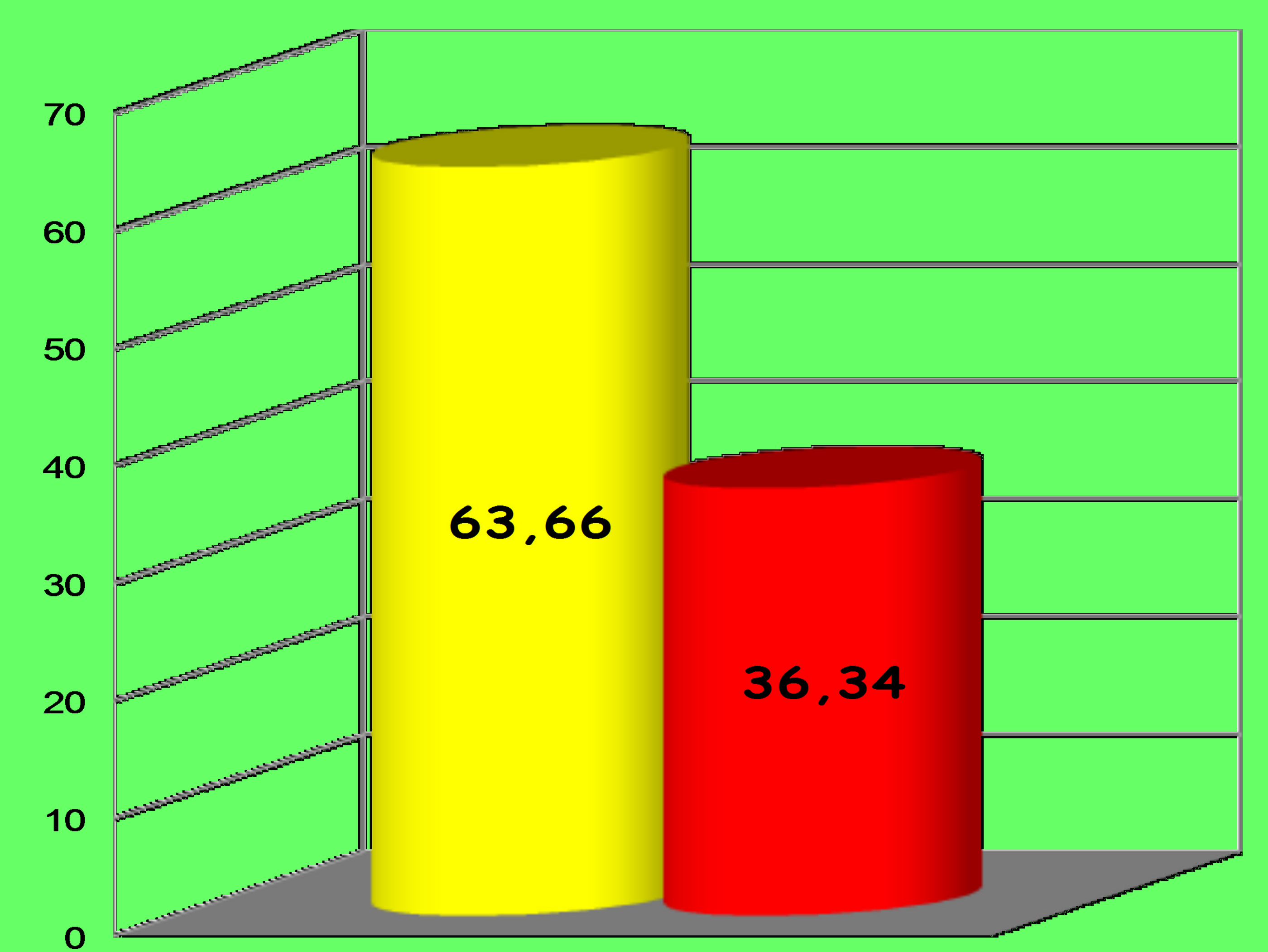

Effective RAI therapy - $63.66 \%$ (64.75\% of F, $59.15 \%$ of $M$ with GD)

Ineffective RAI therapy - 36.34\% (35.25\% of F, $40.85 \%$ of $M$ with GD)

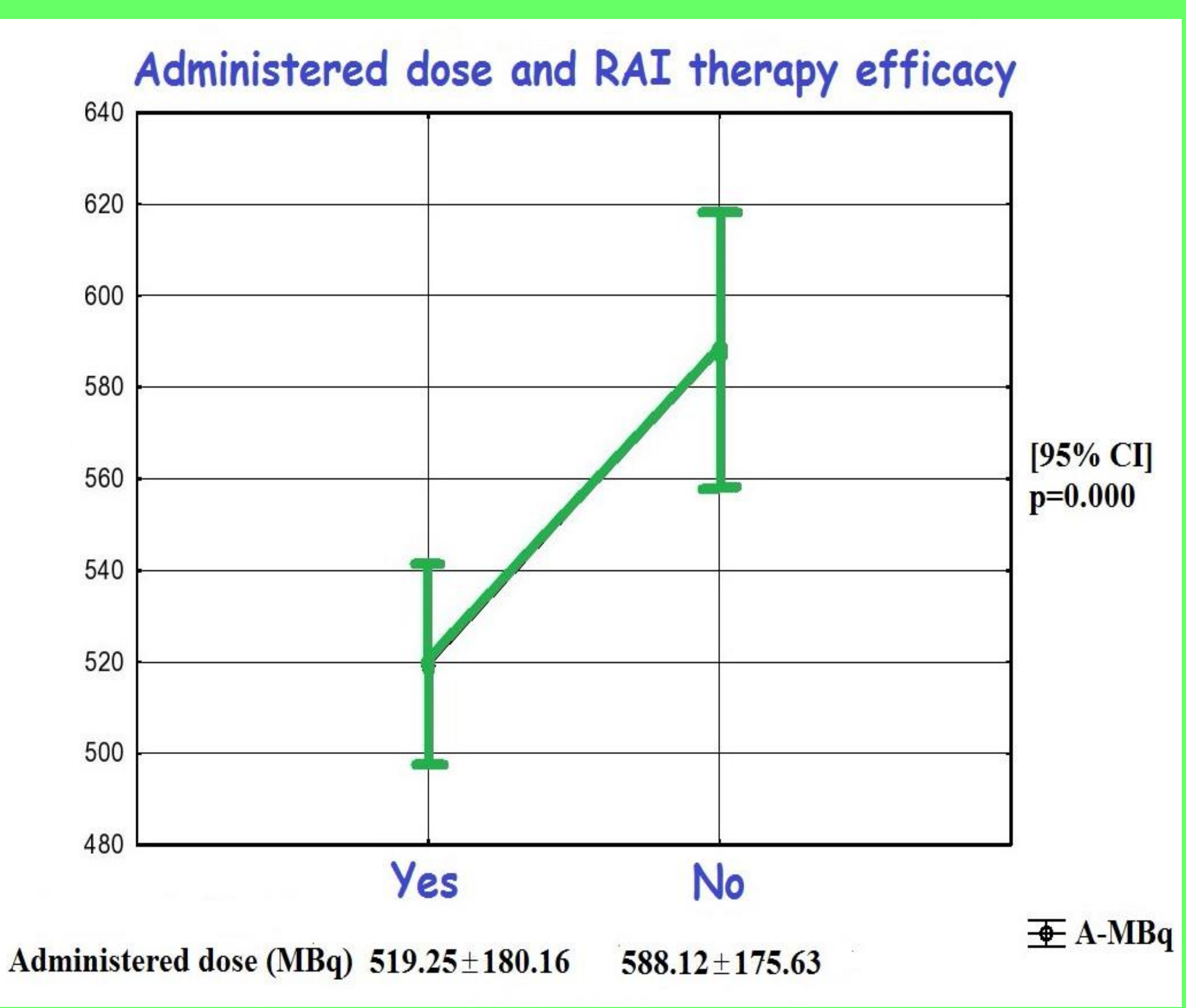

CONCLUSIONS: RAI therapy was effective in $63.66 \%$ of patients with GD. Females responded better to treatment than males. The cure correlated with thyroid mass, RAI 24-h uptake and dose of radioiodine.

$18^{\text {th }}$ European Congress of Endocrinology, 28-31.05.2016 MUNICH, GERMANY 